\title{
Interfirm Relational Strategies and Innovation: the Role of Interfirm Relational Traits and Firm Resources
}

\author{
Sean (Hyunsoon) Yim $^{1}$ • Brett W. Josephson ${ }^{2}$. \\ Jean L. Johnson ${ }^{3}$ - Sanjay R. Sisodiya ${ }^{4}$
}

Published online: 11 April 2015

(C) Springer Science+Business Media New York 2015

\begin{abstract}
Building on relational and resource-based perspectives, this article investigates the indirect effect of interfirm relational strategies (relational proclivity and capability) on firm platform innovation, through their association with key interfirm relational traits (information flows and relational embeddedness). Given differences in firm usage and deployment of resources, the authors examine the moderating effects of two firm-level strategic levers critical to the innovation process: marketing intensity and $R \& D$ intensity. The test of this conceptual model uses primary and secondary data from 237 firms operating in high-tech industries. The results indicate that relational proclivity and capability positively influence interfirm relationship traits of information flows and relational embeddedness. These traits then have profound effects on firm platform innovation. In terms of moderation, the authors demonstrate that marketing intensity improves the ability of relational embeddedness to enhance platform innovation, whereas $R \& D$ intensity improves the ability of information flows to enhance platform innovation. The authors conclude with implications for marketing theory and practice.
\end{abstract}

Sean (Hyunsoon) Yim

sean.yim@wsu.edu

1 Sam and Irene Black School of Business, Penn State Erie, The Behrend College, 5101 Jordan Road, Erie, PA 16563, USA

2 Department of Marketing, George Mason University, 4400 University Drive, Fairfax, VA 22030, USA

3 Department of Marketing and International Business, Washington State University, 380 Todd Addition, Pullman, WA 99164-4730, USA

4 College of Business \& Economics, University of Idaho, 875 Perimeter Dr. MS 3161, Moscow, ID 83844-3161, USA
Keywords Interfirm relationships · Relational strategies · Interfirm relational traits $\cdot$ Innovation

\section{Introduction}

Prior literature indicates that close, partner-style interfirm relationships (IFRs) enable the creation of competitive advantages on various fronts, such as through superior innovation outcomes [84], because they provide the firm with opportunities to acquire valuable resources and capabilities from its partners [66]. For example, close, partner-style IFRs can be critical sources of knowledge, which then can be leveraged to improve innovation outcomes (e.g., [63, 71]). Certain IFR factors are essential to innovation outcomes. Strong information flows among firms means that knowledge critical for innovation is more likely to be shared and available (e.g., [30, 68]), and the level of embeddedness, or strength of ties between IFR partner firms, also influences innovation outcomes [63].

In light of the importance of IFRs to a firm's innovation efforts, questions logically arise about which firm-specific internal capabilities and characteristics drive the development of IFRs with characteristics that enhance innovation. Building from extant literature (e.g., [24, 47]), we argue that firmlevel relational strategies are important, unexplored drivers of IFR development. We draw on interfirm relational theory (e.g., $[9,65]$ ) to propose relational proclivity (willingness to engage in IFRs) and relational capability (ability to make and manage strong IFRs) as components of a firm's relational strategy that influence IFR development, in terms of information flows and relational embeddedness.

Innovation outcomes have been examined from a variety of perspectives, including the volume of innovation $[22,34]$ and radicalness of innovations [13]. We extend those treatments to 
focus on a critically important innovation outcome, namely, platform innovation [79]. Such innovation provides a basis for multiple technology forms and has the potential to be commercialized across an array of products. Essentially, it involves the extent to which a firm's innovation efforts provide a foundation for future options [74]. A firm realizes strong efficiencies in its innovation efforts, which makes platform innovation critical, in which it provides a strong technology pipeline for a firm.

We expect IFR information flows and relational embeddedness patterns to affect the extent of a firm's platform innovation. However, prior research suggests that relational embeddedness can sometimes inhibit innovation outcomes, due to information overload, redundancies, or inertia (e.g., $[26,63,71])$. To explicate this complex relationship, derived from the resource-based view (RBV; e.g., [6, 82]), we suggest that a firm's marketing and $R \& D$ resources (i.e., marketing intensity and R\&D intensity) function as strategic levers that interact with IFR information flows and relational embeddedness to influence a firm's platform innovation.

To test our research question and the specific relationships related to it, as detailed in Fig. 1, we surveyed 237 firms in high-tech industries with regard to their relational strategies and IFRs with suppliers. High-tech industries are an ideal setting for our query, because firms in these industries are characterized by a high degree of relational tendencies, often rely on strong IFRs, and must engage in near constant exploration and replenishment of innovations to maintain their competitive advantage (e.g., [61, 80]). We matched these firm responses with secondary data from the US Patent and Trademark Office to assess platform innovation and from CRSP/COMPUSTAT to gauge the moderators and controls.

Our research thus makes several contributions to marketing theory and practice. First, we provide a rare examination of how interfirm relational strategic postures work to influence productive IFR traits. Second, we contribute to an understanding of innovation outcomes by advancing a novel, strategically important perspective on platform innovation. Because it pertains to innovations that spawn future innovation and provide multiple options for commercialization, a firm's platform innovation speaks to innovation efficiency, a compelling yet unexplored perspective. Third, we cast IFR traits as mediators and explore their implications for innovation outcomes, thus advancing knowledge of IFRs' ability to enhance or imperil innovation outcomes. Fourth, for managers and researchers, we indicate how firm resources and their uses as strategic levers interact with IFR traits to enhance innovation outcomes and ameliorate the potentially detrimental effects of IFR traits on innovation outcomes.

The remainder of this manuscript is organized as follows: We first review literature pertaining to our key constructs; from this literature review, we develop conceptual arguments

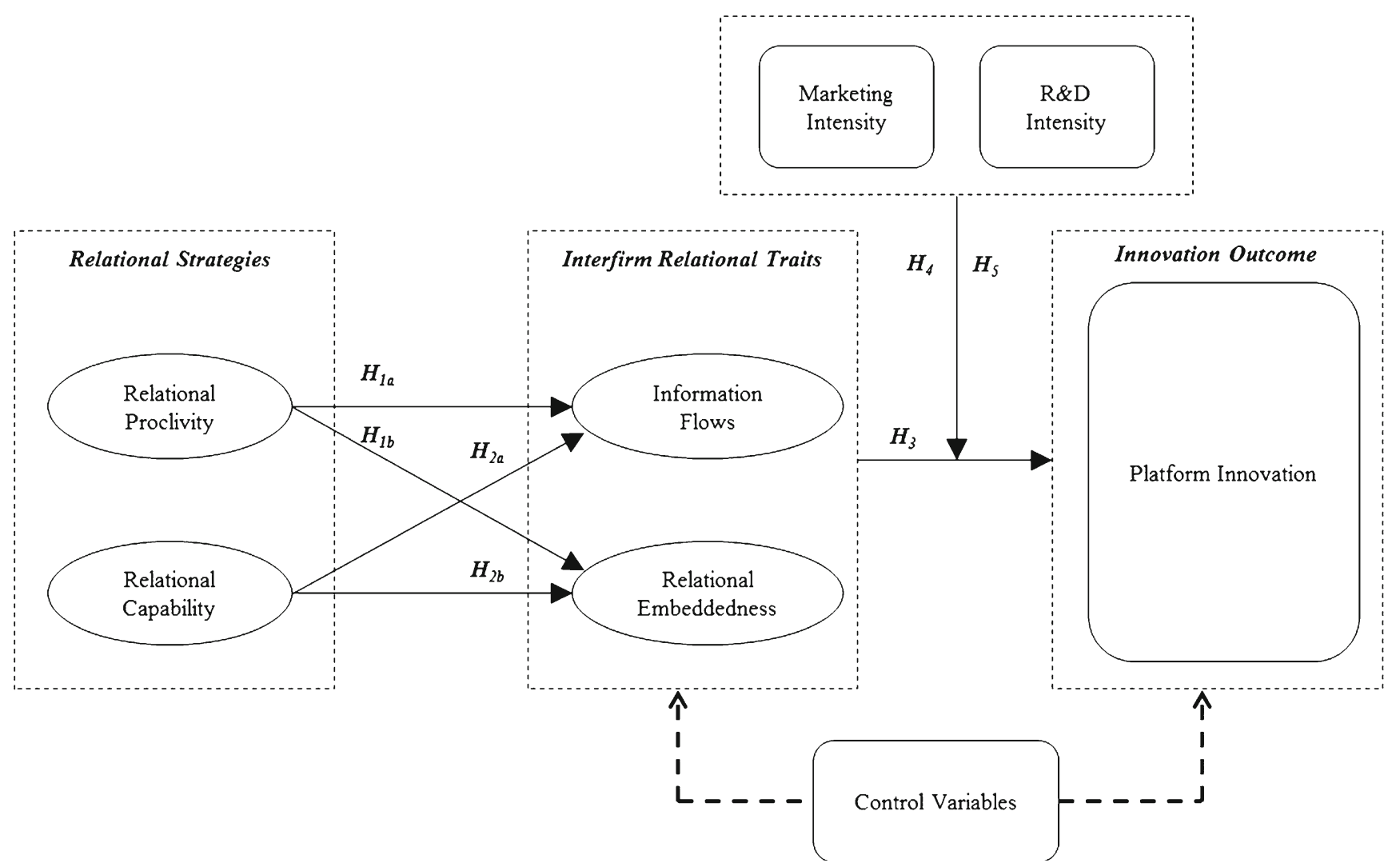

Fig. 1 Conceptual model: the effect of relational strategies on platform innovation 
linking our constructs and derive hypotheses. Next, we discuss our research method, analytical approach, and the empirical tests. Finally, we present an in-depth discussion of our results and conclude with a general presentation of the managerial and theoretical implications of the findings.

\section{Conceptual Background}

\subsection{Relational Strategies}

Previous research suggests that a firm's relational strategies define the role of IFRs in gaining and maintaining strategic advantage, influence how a firm leverages IFRs, and affect the development of IFR traits and characteristics, as well as ultimately a variety of firm outcomes $[18,54,77,81]$. An array of factors constitutes a firm's relational strategy, including its strategic posture toward interfirm relationships and partnering. Arguably, foremost among these factors are a firm's relational proclivity [46] and its relational capability [25].

\subsubsection{Relational Proclivity}

Relational proclivity refers to a firm's willingness to seek out, engage in, and forge closer relationships with selected partners, rather than maintaining arm's-length transactions [46]. A firm with strong relational proclivity sees IFRs as beneficial, generally desires close partner-style IFRs, and actively seeks to participate in such IFRs. In contrast, a firm with less relational proclivity does not perceive the benefits of IFR partnerships. Instead, it may see hazards in close IFRs, such as knowledge leakage or appropriation of strategic advantage [55]. Thus, low relational proclivity means that a firm is not predisposed toward close, partner-style IFRs and even generally avoids them [46]. The degree of relational proclivity varies across firms, despite the seemingly beneficial consequences of closer relationships $[53,73]$. Such variation likely influences the extent to which positive and productive traits develop in a firm's IFRs.

\subsubsection{Relational Capability}

Relational capability refers to a firm's ability to forge, develop, and govern partnerships (e.g., [25, 77]). This capability enables the firm to establish and manage IFRs effectively to ensure the successful acquisition, use, and dissemination of internal and external resources, knowledge, and capabilities [25]. A firm with greater relational capability possesses the ability to maneuver the quagmire of potential IFRs successfully and select a network of partners to facilitate its strategic objectives [32, 39]. Relational capability derives from the stores of knowledge that the firm accumulates as it engages in IFRs (e.g., [47, 57]).
Specifically, three distinct knowledge stores are critical to the development of a firm's relational capability [76]: functional, interactional, and initiation. Functional knowledge stores relate to a firm's knowledge, accumulated from its supply chain operational functions. This knowledge store involves, for example, interfirm IT systems, cost reduction programs, logistics services, and product development and production programs. Interaction knowledge stores represent knowledge about interfirm partnering in terms of the sociopsychological elements of the interfirm interface, such as communication and cooperative programs, interaction patterns, and conflict resolution. Finally, initiation knowledge stores relate to a firm's ability to identify the "right" partner for a deep relationship. They involve judgments regarding which suppliers or firms are potential matches for deep relationships, which firms can be trusted, and where to commit in IFRs. As with relational proclivity, relational capability has important implications for the development of productive and positive IFR traits.

\subsection{Interfirm Relational Traits}

Interfirm relational theory (e.g., $[9,65,67])$ suggests that positive traits in a firm's relationships with its suppliers (or customers) are important for generating productive outcomes. Specifically, relational strategies influence the extents of both information flows and relational embeddedness between a firm and its suppliers [30].

\subsubsection{Information Flows}

Considering the importance of information sharing for producing positive IFR outcomes [14, 30, 49] and innovation outcomes specifically $[26,63]$, we focus on IFR information flows. Following extant literature, we define information flows as the extent of information sharing between a firm and its suppliers [49]. A firm with greater levels of information flows communicates extensively with its IFR partners, essentially acting as an information hub for its IFR partner network $[14,49]$. This role is especially important in relation to a firm's control and collection of pools of strategically important information from its bilateral communication with IFR partners (e.g., [30, 49]).

\subsubsection{Relational Embeddedness}

We define relational embeddedness as the extent of closeness and strength of interaction between a firm and its partners [63]. Research has tended to assume that information sharing is part and parcel of IFRs characterized by high embeddedness (i.e., high tie strength) (e.g., [49, 68]), and the two may often develop in conjunction. However, research also reveals the importance of parsing the complexities of what does and does 
not happen in close IFRs with regard to the implications of information sharing and embeddedness, especially as they relate to innovation outcomes (e.g., [11, 63, 71]). Specifically, information flows are not necessarily productive in highly embedded relationships; thus, it is important to examine their influence independently.

\section{Hypotheses Development}

We argue that a firm's relational strategies affect its innovation outcomes through the development and perpetuation of IFRs with characteristics that influence a firm's innovation efficiency, i.e., the development of platform innovations. Although we expect the relational strategy components to engender relational traits generally considered positive, those traits may not always benefit platform innovation specifically. We explore this effect in greater detail.

\subsection{Relational Strategies and Relationship Traits}

A firm's relational strategies send strong signals to its existing and potential partners about its expectations of IFRs. These strategies influence a firm's IFR traits in several ways. For example, with regard to a firm's relational proclivity, willingness to engage in relationships influences key information sharing with selected partners (e.g., [46]). A firm with high relational proclivity actively seeks and embraces IFRs as valuable strategic assets, which signals openness and trustworthiness that naturally facilitates strong information flows among IFR partners. For similar reasons, we expect that relational proclivity enhances embeddedness in a firm's IFRs. Relational proclivity signals whether a firm values close IFR and its willingness to connect strongly with IFR partners [46]. In addition, a firm with strong relational proclivity is willing to devote financial and managerial resources to its IFR partners. Relational proclivity implies that the firm invests managerial time and effort in its IFRs, encouraging high levels of connectedness and interdependence [46], also known as relational embeddedness. Thus, we posit:

$\mathbf{H}_{\mathbf{1}}$ The greater a firm's relational proclivity, the greater (a) the level of information flows and (b) the level of relational embeddedness in its IFRs.

A firm's relational capability, or ability to make and manage strong, partner-style IFRs [47, 77], influences IFR information flows, because the knowledge stores underpinning relational capability enable a firm to leverage interaction patterns to develop strong communication and thus information flows [68]. Because relational capability involves the identification of potential IFR partners, consistent with a firm's expectations and practices in IFRs, the match between partners naturally facilitates information flows. In general, a firm with high relational capabilities possesses the routines, knowledge structures, and structural know-how to drive flows of vital information, which can be disseminated among through its sets of partners [17, 25]. We also expect relational capability to enhance the extent of embeddedness in a firm's IFRs. Interaction knowledge stores inherent to relational capability result in an IFR interface that enhances trust, commitment, and the depth of the IFR [47]. Moreover, the routines and knowledge involved in IFR initiation ensure that the partner is receptive to these effects. Finally, a firm's knowledge of operational factors in the IFR enables it to offer performance enhancements to its partners, encouraging strong connections and embeddedness. Thus, we posit:

$\mathbf{H}_{\mathbf{2}}$ The greater a firm's relational capability, the greater (a) the level of information flows and (b) the level of relational embeddedness in IFRs.

\subsection{Platform Innovation}

The concept of platform thinking and engineering has emerged as an important aspect of innovation (e.g., [42, 74, 79]). A clear, consensus definition has not emerged, yet platform innovation generally involves the development of new technologies and products with elements and components that can be changed, adapted, and converted to support an array of product offerings (e.g., [42, 79]). Thus, we build on previous literature to cast platform innovation as a new technology, with strong potential for extensions to subsequent innovation iterations. An important feature of platform innovation is its capacity to be converted into an array of product offerings, both currently and in the future, in parallel with subsequent innovation iterations. Thus, our view of platform innovation covers the innovation dimensions of breadth and depth simultaneously (e.g., [27]).

Platform innovation is strategically important, because it provides a foundation for future innovation and a broadened product offering. As a future-oriented innovation strategy, it also initiates a strong options' tree for the firm's new product offerings pipelines $[10,45]$. By designing and integrating architecture with opportunities for future innovation iterations, product configurations, and advancements, platform innovation reduces costs [74]. It can greatly increase the efficiency of a firm's innovation efforts and new product development processes (e.g., $[1,42])$. For example, many automobile manufacturers (e.g., Ford Motor Company, General Motors, Toyota) design car chassis that provide technology frameworks for further technology advances and are integrated into multiple brand lines and future models. This approach increases the efficiency and effectiveness of their innovation programs. 


\subsection{Relational Traits and Platform Innovation Outcomes}

We expect IFR information flows and relational embeddedness to affect platform innovation, albeit in different and somewhat unexpected ways. Because platform innovation pivots on information for both the breadth and depth of the innovation, strong IFR information flows are important. Strong information flows entail significant bilateral sharing of technical information among IFR partners. The firm can leverage this easily flowing information to develop innovation advancements [63]. Bilateral information flows between a firm and its suppliers also can result in the relaxation of structural boundaries (i.e., diminished rigidity). A firm may become semipermeable, further accommodating the interfirm flow of information and knowledge resources (e.g., [15]). Such increased knowledge resources substantially bolster the development of innovations that offer deep technological advances. The strong information flows also provide a firm with a sense of where to focus its innovation efforts in terms of breadth. Sharing of key information among IFR partners thus can be a springboard, such that a firm tests ideas and gathers important inputs and insights into innovation success. A firm armed with broadened knowledge and information provided by IFRs can identify technologies with a strong future trajectory and a solid foundation for subsequent innovation generations. In addition, with such knowledge, a firm can more easily identify technologies with broad-based applications to convert readily to an array of product offerings. Thus, we posit:

$\mathbf{H}_{\mathbf{3}}$ The greater the information flows in a firm's IFRs, the higher the level of its platform innovation.

Substantial literature details the benefits of strong, close connections in IFRs, or relational embeddedness (e.g., [51, $62,72])$. However, the evidence with regard to the impact of relational embeddedness on innovation outcomes is less clear. Close relationships facilitate resource exchange and knowledge codevelopment, which could positively affect some but not all innovation outcomes [11, 71]. For example, relational embeddedness can signify information redundancy [36]. Embedded IFR partners may share the same information and knowledge bases with little or no unique or new information to be gained. The absence of novel information and knowledge can inhibit innovation [11, 63, 84]. Although some research indicates that information redundancy in highly embedded IFRs is not necessarily a problem (e.g., [11]), other studies assert that certain factors come into play that restrict innovation progress (e.g., [63]). Relational embeddedness signifies that a firm is locked in to specific relationships, which leads to rigidity and inertia (e.g., [8]). The IFR lock-in that comes with relational embeddedness may mean a loss of the necessary flexibility for platform innovation development.
Such locked-in IFRs also might alienate potentially important factions in an IFR relational network, instigating relational resistance to a firm's innovation efforts and hindering its expansion ability (e.g., [31]). Finally, embeddedness in IFRs may leave a firm vulnerable to knowledge leakage and the appropriation of competitive advantages [55], which can inhibit the development of platform innovation. Thus,

\section{$\mathbf{H}_{\mathbf{3 b}}$ The greater the relational embeddedness in a firm's IFRs, the lower the level of its platform innovation.}

\subsection{Moderating Role of Firm Resources}

A firm's resources are a critical source of competitive advantage (e.g., [6, 69, 82]). In the RBV [6], resources involve any tangible or intangible asset, at least semipermanently connected to the firm, that can be viewed as a strength [82]. All firms have some resource endowments, but they are highly heterogeneous in their resource levels and deployment of those resources toward strategic issues, initiatives, and opportunities [6]. Given this heterogeneity, firm resources and their usage provide a critical context for their innovation activities. We build on RBV perspectives (e.g., [6, 78]) to consider how two key firm resources, marketing intensity and R\&D intensity, serve as strategic levers to influence the relationship between IFR traits and platform innovation.

\subsubsection{Moderating Role of Marketing Intensity}

Marketing intensity refers to the level of a firm's strategic focus and resources spent on marketing and thus depicts its relative resource deployment to vital marketing activities. It involves the extent of a firm's market-sensing activities and abilities [78]. A firm with greater marketing intensity has competitive strengths in creating, communicating, and delivering value (e.g., [3, 59]). Moreover, firms with greater marketing resources and subsequent deployment of those resources, or marketing intensity, can generate market information about market needs, trends, and opportunities [50]. Marketing intensity pertains to a firm's outside-in perspective; it is able to sense market opportunities and internalize them into strategic actions and options (e.g., [20, 50]). From this outside-in perspective, we theorize the role of marketing intensity as an influence on the relationship between IFR traits and platform innovation.

Specifically, we expect marketing intensity to mute the positive effect of high IFR information flows on platform innovation. At first glance, the increased information accrued from market-scanning activities should amplify the positive effect of supplier information. However, too much information actually impedes innovation (e.g., [21, 56]). The firm leverages its marketing intensity to gather and internalize 
marketplace knowledge (e.g., information about customer needs and demands and technology disruptions; [78]). This external information merges with the IFR information flow to increase the potential for information overload and for information redundancy [75]. The supplier information overlaps with the marketplace information, producing constraints on the firm's ability to integrate, disseminate, and act on its new information stores. Simply put, a firm receives an overload of information that it is ill-equipped to handle, deliberate, or act upon [75]. This form of bounded rationality - too much information from too many sources - leaves a firm vulnerable to lackluster innovation outcomes. The firm is not able to improve innovation depth or breadth. Therefore, due to information overload and overlap from both the supplier and customer sides, we predict that greater marketing intensity attenuates the relationship between information flows and platform innovation.

In contrast, marketing intensity should buffer the negative effect of relational embeddedness on platform innovation. Because of the scanning activities involved, marketing intensity can generate valuable new information about potentially broad and deep innovations, namely, the platform. This novel information can offset potential redundancies in information in highly embedded supplier IFRs. High relational embeddedness implies effective information exchanges in IFRs, but the gain may be minimal due to redundancy. Market sensing provides information that is unique and novel, thus mitigating redundancy concerns. As such, a firm can improve its innovation efficiency and reach, by leveraging unique information from the customer side through marketsensing activities that have been made possible by strong marketing resources, to compensate for its information redundancy on the supplier side. The unique and novel information and knowledge gained from improved market-sensing activities then can be leveraged with an efficient information exchange among highly embedded relational partners to develop more efficient and effective innovative product offerings that produce a strong option tree. We posit:

$\mathbf{H}_{\mathbf{4}}$ A firm's marketing intensity reduces (a) the positive association between information flows in its IFRs and the level of its platform innovation and (b) the negative association between relational embeddedness in its IFRs and the level of its platform innovation.

\subsubsection{Moderating Role of $R \& D$ Intensity}

We consider a firm's R\&D intensity as its resources for R\&D activities and the relative strength of its exploratory actions and abilities [58]. As such, R\&D intensity represents a firm's ability to leverage its existing knowledge, resources, and capabilities to develop successful new products [41]. Moreover, $R \& D$ intensity indicates a firm's commitment to continual innovation [35]. Extant literature notes that R\&D intensity has a strong impact on a variety of innovation outcomes [70], suggesting its importance as a firm resource that can be used to influence the relationship between IFR traits and platform innovation. Moreover, R\&D intensity represents an inside-out perspective [20], from which we theorize a role in the relationship between IFR traits and a firm's platform innovation.

Because R\&D intensity indicates a firm's strategic focus and strength in exploratory actions, we posit that it amplifies the relationship between IFR information flows and platform innovation. Strong IFR information flows mean that valuable information and channel spillovers are available to the firm and its IFRs. Firms with strong R\&D intensity possess the requisite ability and internal expertise to capitalize on the information-rich situation provided by the IFR information flows. Strong R\&D intensity also enables the firm to harness knowledge resources from its IFRs and leverage that knowledge to produce innovations that are both broad and deep, so that they can be converted to meet multiple needs, extended across a range of offerings, and provide options to the firm. In this way, the use of R\&D intensity, combined with valuable IFR information flows, drives improved innovation outcomes. Without the requisite $R \& D$ intensity, firms would not possess the internal knowledge and expertise needed to leverage their IFR information to improve their innovation. Thus, firms use their R\&D intensity as a strategic lever to enhance the positive effect of IFR information flows on their platform innovation.

In terms of the effect on the relational embeddedness-platform innovation relationship, we expect R\&D intensity to amplify the negative effect, because R\&D intensity involves leveraging the knowledge and capabilities presently available in the firm to produce novel innovations. The knowledge coming into the firm from highly embedded IFRs is likely redundant, so it may serve to distract and overwhelm the innovating firm's internal effort, rather than add strength or resources [2]. The firm tries to use its R\&D expertise and knowledge to drive innovation but is significantly hindered by the lack of unique information flowing into its structural boundaries. Research suggests that highly embedded relationships can derail a technology development trajectory by limiting creativity and restricting access to fresh ideas [2]. This benefit, coupled with the firm's struggle to sort out and evaluate knowledge redundancy from the same highly embedded IFRs, combines to hinder firm platform innovation. In essence, the combination of strong R\&D and highly embedded IFRs likely results in distracted and ineffectual innovation initiatives for a firm. Thus, we predict:

$\mathbf{H}_{5} A$ firm's $R \& D$ intensity increases (a) the positive association between information flows in its IFRs and the level of its platform innovation and (b) the negative association between the relational embeddedness in its IFRs and its level of platform innovation. 


\section{Methodology}

\subsection{Research Context and Data Collection}

We collected data from firms in industries that require the use of advanced technologies, are under constant pressure to innovate and introduce new products, and are likely to build relationships among channel members (e.g., [61, 80]). Our sample included firms operating in advanced materials, biotechnology, computer software, medical, and pharmaceutical industries. In preliminary field interviews, managers noted the importance and relevance of relational strategies with their upstream channel members and constant new product development for sustaining their competitive positions in markets. We used these managers' input to validate our research model and nomological net.

Contact information for marketing and new product development managers of firms in the selected industries was obtained from a commercial list provider. Rigorous prescreening by mail (i.e., postcards) and telephone calls identified 532 possible study participants. We mailed survey packets, including a cover letter describing the project, the survey instruments, and two incentives (i.e., $\$ 5$ and an opportunity to receive summary results). We followed a mixed mode method for this data collection and included both mail and electronic surveys. The survey generated 237 responses, for a response rate of $44.5 \%$, which compares favorably with extant literature (e.g., [33]).

We assessed nonresponse bias by comparing early and late responders [5] and responding to nonresponding firms on certain firm traits (e.g., number of employees, sales, and financial performance). The tests indicated no differences, reducing concerns of possible response bias. We also verified the qualifications of the key informants, as suggested in prior literature (e.g., [52]). The qualification screening indicated that $55.7 \%$ of the informants were new product development managers, $36.3 \%$ senior executives, and $8.0 \%$ product managers. The average tenure period in the firms was 12.9 years, and respondents had been in their current positions for 6.7 years. These managers considered themselves highly qualified to discuss their firm's relational strategies, R\&D, and new product development activities (seven-point scale, $M=6.49, \mathrm{SD}=0.57$ ). For measures of innovation, we used the US Patent and Trademark Office (USPTO) and an online patent data provider (i.e., Patent Integration) to obtain firm patent data. We then matched patents with firm survey responses, resulting in a final sample of 154 firms. We calculated additional measures using data from the CRSP/COMPUSTAT database.

\subsection{Measures}

Our measures are based on extant literature when available (see Appendix 1). Considering the preponderance of evidence indicating that relationships with upstream partners improve innovation outcomes (e.g., [43]), we focused on firm interactions with key suppliers.

\subsubsection{Relational Strategies and Interfirm Relational Traits}

We measured relational capability in a way consistent with previous literature (e.g., [76]). Drawing from the perspective of interfirm knowledge stores [47], we used the scale developed by Sisodiya et al. [76] but added an initiation ability component (see Appendix 1). Initiation ability is associated with selecting and assessing potential partners, evaluating those selected partners, and maintaining extant relationships. We measured relational proclivity using a scale adapted from Johnson and Sohi [46]. We also adapted existing scales to develop measures of information flows [68] and relational embeddedness [63]. Appendix 1 contains the scale items.

\subsubsection{Platform Innovation}

To capture a firm's platform innovation, we collected published patents assigned to the focal firm between 2006 and 2008 (hereafter, the innovation measure window) from both the USPTO and an online patent data provider. The published patent information provides the benchmark patent for counting forward citations. Truncation issues associated with forward patent citation counts led us to adopt a multiyear patent data collection (e.g., [12]). In terms of a firm's forward citation, we only considered self-citation counts, which refer to forward citations by the same patent assignee, namely, the firm (e.g., [40]). Thus, a self-citation indicates the extent to which a firm's technologies are leveraged by its future innovations.

We measured platform innovation as the ratio of the sum of self-citation counts to the total number of granted patents to firm $i$ during the innovation measure window (e.g., [48]). This operationalization of platform innovation reflects the extent of internalization of a firm's own technological knowledge in its future innovation, as in Eq. 1:

Platform $_{i}=\frac{\sum_{k=1}^{N_{i}} \sum_{t}^{2012}[\text { Patent }(k) \text { ForwardCitations }]_{t}}{N_{i}}$,

w h e r e $N_{i}=\sum I_{k t}$.

$I_{k t}=1$ if Patent $(k)$ was granted to Firm $i$ at time $t$, where $t=[2006,2007,2008]$

$I_{k t}=0$, otherwise

\subsubsection{Moderating Variables}

We include two moderating variables in our model: marketing intensity and R\&D intensity. To determine marketing 
intensity, we calculated a firm's 3-year average ratio of marketing expenditures (i.e., sales and general administration) to its total revenue. We then log transformed this average value. Similarly, we calculated each firm's 3-year average ratio of $R \& D$ expenditures to its total revenue during the measurement window then took the logarithmic transformation of the average.

\subsubsection{Control Variables}

We include three primary control variables. First, environmental turbulence influences firm innovation outcomes (e.g., [85]). Therefore, consistent with previous literature (e.g., $[28,64])$, we control for industry turbulence, or the ratio of an industry's standard deviation in sales to its mean value of sales, and for technology turbulence, i.e., the ratio of industrylevel R\&D expenditures to industry-level sales. Second, firm size is a significant predictor of innovation outcomes (e.g., [13]), which we calculated as the natural log of a firm's total assets. Third, we controlled for any additional industry differences by including industry dummy variables, using the first digit of a firm's primary standard industrial classification number. Table 1 summarizes the measures calculated from secondary data, their operationalization, and the data sources. Table 2 contains the descriptive statistics and correlation matrix.

\subsection{Results}

Traditional covariance-based structural equation modeling (SEM) techniques are inappropriate for our study context, because our measure of relational capability is a formative construct. To deal with this type of construct, partial least squares (PLS) SEM represents the best option [16]. An advantage of PLS-SEM is that it readily accommodates structural models with reflective and formative measures $[16,83]$, which constitute our study.

\subsubsection{Measure Validation}

We conducted tests of measurement reliability and validity, as suggested by Chin [16]. For our reflective constructs (i.e., relational proclivity, information flows, and relational embeddedness), all item loadings were greater than 0.7 , and the composite reliabilities were greater than 0.87 , which satisfied conventional criterion. The average variances extracted (AVEs) exceeded 0.50 (Appendix 1). In Table 2, the values on the diagonals, which indicate AVEs, also reveal satisfactory discriminant validity for the reflective constructs [29]. Overall, our reflective measures possess adequate reliability and validity.

Traditional assessments of construct validity and reliability are inappropriate for formative constructs [38], so we checked

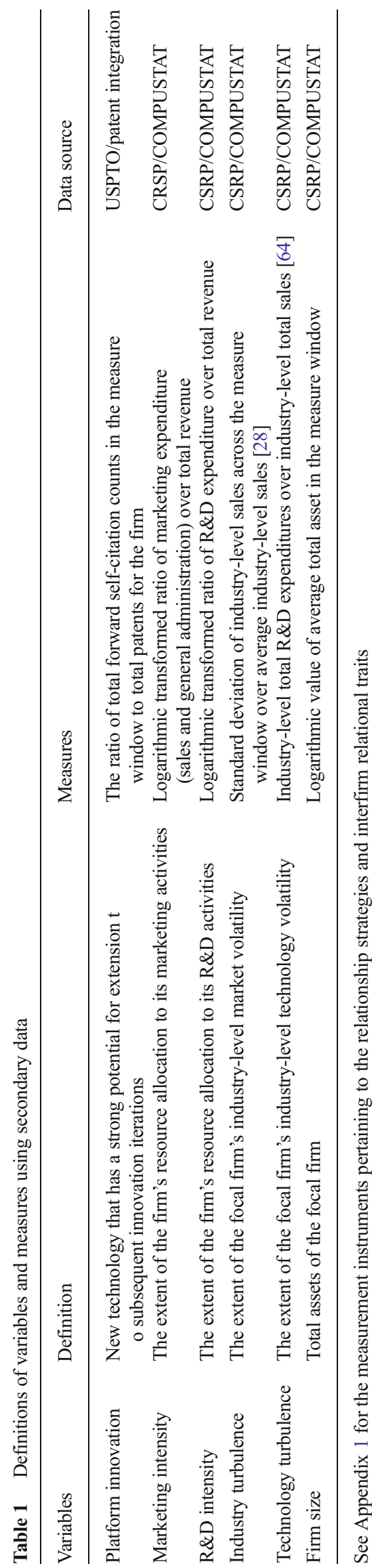


Table 2 Descriptive statistics and correlation matrix

\begin{tabular}{|c|c|c|c|c|c|c|c|c|c|c|c|c|}
\hline \multirow[t]{2}{*}{ Variables } & \multirow[t]{2}{*}{ Mean } & \multirow[t]{2}{*}{ Std. dev. } & \multicolumn{10}{|c|}{ Correlation matrix } \\
\hline & & & 1 & 2 & 3 & 4 & 5 & 6 & 7 & 8 & 9 & 10 \\
\hline Platform innovation & 0.65 & 1.95 & N.A. & & & & & & & & & \\
\hline Relational proclivity & 3.77 & 0.63 & 0.14 & 0.59 & & & & & & & & \\
\hline Relational capability & 4.71 & 0.93 & $0.19^{*}$ & $0.32^{*}$ & N.A. & & & & & & & \\
\hline Information flows & 3.00 & 0.78 & 0.14 & $0.22^{*}$ & $0.49^{*}$ & 0.63 & & & & & & \\
\hline Relational embeddedness & 3.74 & 0.72 & 0.13 & $0.39^{*}$ & $0.68^{*}$ & $0.53^{*}$ & 0.75 & & & & & \\
\hline Marketing intensity & 0.38 & 0.67 & -0.07 & -0.06 & -0.04 & $-0.27^{*}$ & -0.02 & N.A. & & & & \\
\hline $\mathrm{R} \& \mathrm{D}$ intensity & 0.62 & 1.35 & $0.18^{*}$ & 0.02 & 0.01 & -0.10 & 0.03 & $0.26^{*}$ & N.A. & & & \\
\hline Industry turbulence & 3.37 & 0.76 & 0.00 & 0.01 & -0.03 & -0.02 & -0.06 & 0.03 & 0.10 & N.A. & & \\
\hline Technology turbulence & 0.08 & 0.03 & 0.07 & 0.05 & 0.05 & -0.13 & 0.04 & 0.13 & $0.30^{*}$ & $0.52^{*}$ & N.A. & \\
\hline Firm size & 5.79 & 2.22 & 0.03 & 0.01 & $0.24^{*}$ & $0.28^{*}$ & $0.19^{*}$ & $-0.19^{*}$ & $-0.35^{*}$ & $-0.18^{*}$ & $-0.33^{*}$ & N.A. \\
\hline
\end{tabular}

$n=154$. The average variance extracted is on the diagonal, and correlations are on the off-diagonal

N.A. not applicable items

${ }^{*} p<0.05$

for formative construct validity using matched holdout samples, along with multicollinearity checks among items [23, 38 . The condition indices for each dimension range between 21.38 and 23.56 for the holdout sample and 19.29-25.06 for the matched sample, so the indices are below the threshold of 30 [7]. In addition, we tested multicollinearity at the item level by calculating the variance inflation factors (VIFs) and condition indexes [7]. The VIF values for each dimension of relational capability were well below the cutoff criterion of 10 (i.e., 1.48-3.45), indicating no issues of multicollinearity in our construct [23].

\subsubsection{Hypotheses Testing}

We report the results of our model estimation in Table 3. Consistent with Chin [16], we estimated the coefficient of determination $\left(R^{2}\right)$ then ran PLS to estimate the path coefficients and standard errors. The $R$-squared values of the three endogenous variables (i.e., information flows, relational embeddedness, and platform innovation; ranging from 0.32 to 0.55 ) suggest satisfactory explanatory power.

Our hypotheses consist of three main predictions: (1) $\mathrm{H}_{1}$ and $\mathrm{H}_{2}$ pertain to the effect of relational strategies on information flows and relational embeddedness, (2) $\mathrm{H}_{3}$ involves the effect of information flows and relational embeddedness on platform innovation, and (3) $\mathrm{H}_{4}$ and $\mathrm{H}_{5}$ suggest the moderating effects of marketing intensity and R\&D intensity. We found no statistical support for $\mathrm{H}_{1 \mathrm{a}}(b=0.01, p>0.10)$; relational proclivity did not have a significant effect on a firm's information flows. However, in support of $\mathrm{H}_{1}$, greater relational proclivity positively influenced a firm's relational embeddedness $(b=0.13, p<0.01)$. We also confirmed $\mathrm{H}_{2}$, in that a greater level of relational capability positively influenced both information flows $(b=0.53, p<0.01)$ and relational embeddedness $(b=0.66, p<0.01)$.

Greater information flows, in turn, increased firms' platform innovation $(b=0.09, p<0.01)$, whereas relational embeddedness had a significant negative effect $(b=-0.09$, $p<0.01$ ), in support of both $\mathrm{H}_{3 \mathrm{a}}$ and $\mathrm{H}_{3 \mathrm{~b}}$. Moreover, marketing intensity and R\&D intensity moderated these significant main effect relationships. With regard to $\mathrm{H}_{4}$, marketing intensity muted the positive relationship between information flows and platform innovation $(b=-1.13, p<0.01)$, whereas it positively moderated the negative relationship between relational embeddedness and the platform innovation $(b=1.04, p<0.01)$, as we predicted. Figure 2, panels a and b, graphically depicts the nature of the interaction effects. High marketing intensity inhibits the ability of information flows to drive platform innovation but enables relational embeddedness ability to create more platform innovation. Finally, for $\mathrm{H}_{5}$, we found that $\mathrm{R} \& \mathrm{D}$ intensity enhanced the positive effect of the information flows on platform innovation $(b=3.98, p<0.01)$ but exacerbated the negative effect of the relational embeddedness on the platform innovation $(b=-2.57, p<0.01)$. Figure 3 , panels a and $\mathrm{b}$, graphically depicts the nature of these interactions. When R\&D intensity is high, information flows exert a stronger positive effect on platform innovation, but relational embeddedness has an even more negative effect on platform innovation. These findings were consistent with our expectations.

\section{Discussion}

In today's turbulent business landscape, collaboration with partners is one of the most promising strategies for improving 
Table 3 Effect of relationship strategies on innovation outcome

\begin{tabular}{|c|c|c|c|c|c|c|c|}
\hline \multirow[t]{2}{*}{ Variables } & \multirow[t]{2}{*}{ Hypotheses } & \multicolumn{2}{|c|}{ Information flows } & \multicolumn{2}{|c|}{$\begin{array}{l}\text { Relational } \\
\text { embeddedness }\end{array}$} & \multicolumn{2}{|c|}{ Platform } \\
\hline & & B & $(\mathrm{SE})$ & B & (SE) & B & $(\mathrm{SE})$ \\
\hline \multicolumn{8}{|l|}{ Relational strategies } \\
\hline Proclivity & $\mathrm{H}_{1 \mathrm{a}-1 \mathrm{~b}}$ & 0.01 & $(0.02)$ & 0.13 & $(0.01)^{* * *}$ & 0.09 & $(0.02)^{* * *}$ \\
\hline Capability & $\mathrm{H}_{2 \mathrm{a}-2 \mathrm{~b}}$ & 0.53 & $(0.02)^{* * *}$ & 0.66 & $(0.02)^{* * *}$ & 0.16 & $(0.03)^{* * *}$ \\
\hline \multicolumn{8}{|l|}{ Interfirm relational traits } \\
\hline Information flows (IF) & $\mathrm{H}_{3 \mathrm{a}}$ & & & & & 0.09 & $(0.02)^{* * *}$ \\
\hline Relational embeddedness (RE) & $\mathrm{H}_{3 \mathrm{~b}}$ & & & & & -0.09 & $(0.03)^{* * *}$ \\
\hline \multicolumn{8}{|l|}{ Moderators } \\
\hline Marketing intensity (MI) & & & & & & 0.53 & $(0.12)^{* * *}$ \\
\hline R\&D intensity (RDI) & & & & & & -1.32 & $(0.22)^{* * *}$ \\
\hline \multicolumn{8}{|l|}{ Interactions } \\
\hline $\mathrm{IF} \times \mathrm{MI}$ & $\mathrm{H}_{4 \mathrm{a}}$ & & & & & -1.13 & $(0.14)^{* * *}$ \\
\hline $\mathrm{RE} \times \mathrm{MI}$ & $\mathrm{H}_{4 \mathrm{~b}}$ & & & & & 1.04 & $(0.16)^{* * *}$ \\
\hline $\mathrm{IF} \times \mathrm{RDI}$ & $\mathrm{H}_{5 \mathrm{a}}$ & & & & & 3.98 & $(0.44)^{* * *}$ \\
\hline $\mathrm{RE} \times \mathrm{RDI}$ & $\mathrm{H}_{5 \mathrm{~b}}$ & & & & & -2.57 & $(0.32)^{* * *}$ \\
\hline \multicolumn{8}{|l|}{ Control variables } \\
\hline Industry turbulence & & & & & & -0.01 & $(0.02)$ \\
\hline Technology turbulence & & & & & & 0.08 & $(0.02)^{* * *}$ \\
\hline Firm size & & 0.16 & $(0.02)^{* * *}$ & 0.03 & $(0.01)^{*}$ & 0.08 & $(0.01)^{* * *}$ \\
\hline Ind1 & & 0.00 & $(0.02)$ & -0.05 & $(0.02)^{* * *}$ & -0.05 & $(0.02)^{* *}$ \\
\hline Ind2 & & 0.00 & $(0.00)$ & -0.06 & $(0.01)^{* * *}$ & 0.05 & $(0.01)^{* * * *}$ \\
\hline Ind3 & & 0.02 & $(0.02)$ & -0.09 & $(0.02)^{* * *}$ & -0.03 & $(0.02)$ \\
\hline Ind4 & & -0.08 & $(0.01)^{* * *}$ & -0.13 & $(0.01)^{* * *}$ & 0.02 & $(0.01)$ \\
\hline$R^{2}$ & & 0.35 & & 0.55 & & 0.32 & \\
\hline
\end{tabular}

firm outcomes, such as innovation. As such, firms leverage and purposively seek interfirm relationships to improve their competitive position. These relational strategies result in firms developing interfirm relational traits, and the characteristics of those traits have profound implications for innovation. Specifically, they affect the quantity and quality of the information that flows among collaborating members. The extent of innovation success is strongly influenced by the nature of a firm's IFR strategic focus and the IFR traits that result from that focus. These findings address several gaps in marketing literature.

First, we show that relational strategies (i.e., relational proclivity and relational capability) and the relational capital they produce positively influence information flows with suppliers and the firm's relationship strength with those suppliers. A strong relational proclivity and willingness to engage in relationships appear to signal desirable characteristics and traits to potential relational partners, improving the firm's ability to achieve specific IFR status (e.g., [47]). Greater willingness to be in relationships signals openness, as well as a belief that such relationships are important and worthwhile. A strong relational capability, or the ability to engage in meaningful relationships, also highlights desirable characteristics for potential partners, strengthening the firm's ability to leverage and create important IFR partners. Greater ability sends strong signals that the firm is trustworthy and willing to commit [60]. Together, these effects strengthen key IFR traits: facilitating information flows and close reciprocal relationships with suppliers.

Second, our results show that these IFR strategies and subsequent IFR traits have a significant influence on a firm's platform innovation. Specifically, acting as the information hub for its suppliers (i.e., information flows) generates novel and unique information for the firm, which it can leverage to improve the breadth and depth of its innovations. However, redundancy and accumulation of information from only a few suppliers, through strong relational embeddedness, hinders the firm's ability to improve its innovation efficiency and expand its technology scope. We found boundary conditions for these main effects by including two moderating conditions: marketing intensity and R\&D intensity.

The use of marketing intensity as a strategic lever buffered the negative effect of relational embeddedness on platform innovation by generating valuable new information about 
a Information flows

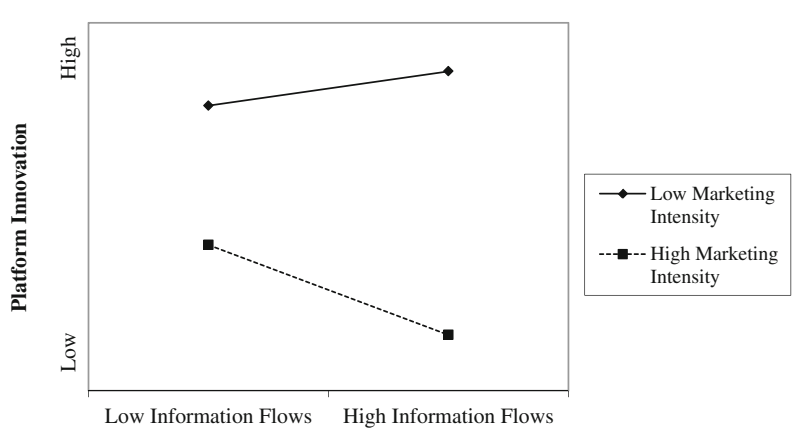

b Relational embeddedness

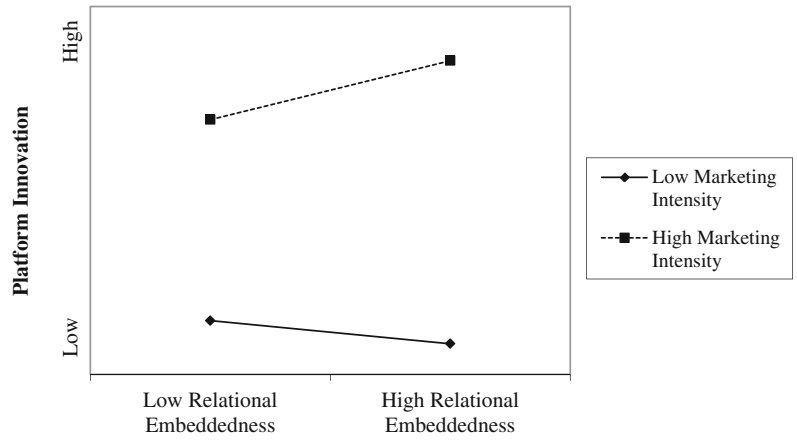

Fig. 2 Moderation by marketing intensity. a Information flows. b Relational embeddedness

potential broad and deep innovations that the firm was previous lacking. The use of R\&D intensity was best as a strategic lever when coupled with unique knowledge and information that came from the firm being the central information hub in its IFRs. Greater strategic focus on exploration provides the firm with the requisite knowledge to leverage unique information from suppliers to improve the scope and efficiency of their innovation.

\subsection{Theoretical Implications}

Our study makes several important contributions to marketing literature. First, we provide a more holistic view of relationship marketing's impact on innovation, in general, and IFRs specifically. Marketing literature (e.g., [60]) frequently views IFRs from only a dyadic perspective, departing from observable IFR behavior. Recognizing this limitation, we have sought to address IFRs with the realization that firms engage in relationships with more than one partner at any one time, resulting in a network of IFR partners, and the focal firm enjoys certain characteristics of being associated with certain IFR partners (information flows and relational embeddedness). This rich theoretical context offers novel insights into key marketing outcomes and behaviors [63]. We present a nomological model that more accurately captures how IFRs affect firm outcomes, which should help expand a Information flows

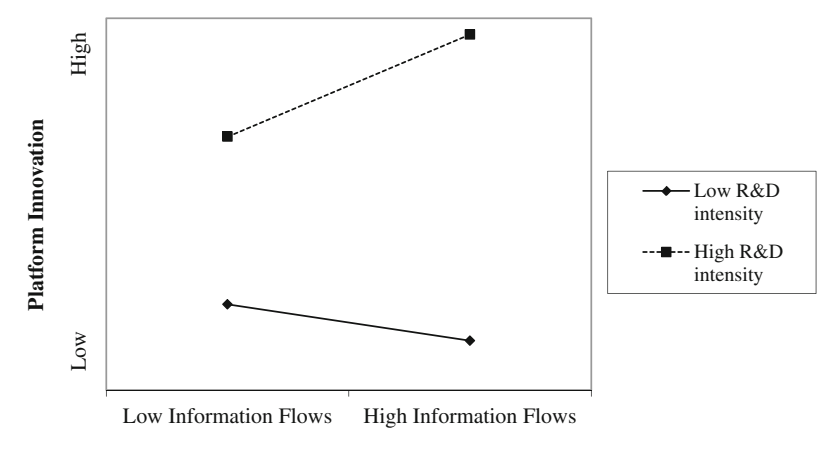

b Relational embeddedness

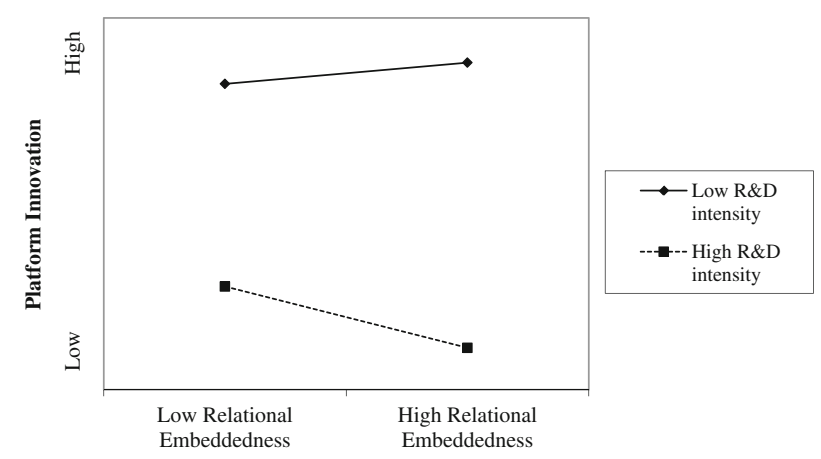

Fig. 3 Moderation by R\&D intensity. a Information flows. b Relational embeddedness

the theoretical boundaries of marketing's understanding of the IFR phenomena.

Second, we contribute to IFR literature that investigates information flows (e.g., [71]) and relational embeddedness (e.g., [63]) in marketing by providing empirical evidence of marketing-relevant antecedents. Scant literature addresses any notion of key contexts, conditions, resources, or capabilities that result in the formation of key IFR trait characteristics (e.g., [44]). Our findings thus expand the known parameters of the various aspects of IFRs in marketing, by demonstrating that relational strategies are legitimate and significant predictors of key interfirm relational traits.

Third, we contribute to marketing knowledge regarding an important type of innovation (platform) and how it is influenced by critical firm interfirm traits [37, 41]. Specifically, the indirect effect of relational marketing components on platform innovation, through IFR traits, helps enrich the theoretical knowledge base about the actions a firm can take to help create more lasting and meaningful innovations. In addition, we expand the theoretical notion of platform innovation in marketing literature by incorporating the creation of future strategic innovation options [74]. A firm's platform innovation, as a source of strategic future options, affects its subsequent new product development (NPD) and enhances the efficiency of future NPD processes, which then allow it to gain a superior competitive position. Although this observation is 
limited to our findings, it implies that IFRs should be included as key components of tactics to build strategic options through innovation.

\subsection{Managerial Implications}

Our research also provides several implications for practice. First, characteristics of IFRs that form from relational strategies affect a firm's critical outcomes in decisive ways. A firm's relational strategies (i.e., relational proclivity and capability) facilitate its role as an information hub for its suppliers and its ability to develop close reciprocal relationships with its suppliers. Managers can configure their relational strategies to promote information flows among the IFR partners, according to their proclivity or ability to engage in relationships. They also should determine carefully if becoming an information hub in an IFR partnership or having embedded IFRs is more important for their firm and their future strategic activities. As we have shown, these activities have profound impacts on firms' innovation outcomes.

Moreover, managers should actively maintain their information flows with their suppliers if they wish to improve their firm's innovation efficiency. They should purposively seek to engage a diverse pool of suppliers to ensure that they are gathering key pieces of information to develop unique, efficient products and services. If the firm resides in the middle of the information flows, it must balance its role as an influencer (or controller) with its role as a motivator. Control over information flows has advantages in an efficient NPD process (e.g., [2]). Marketing managers should encourage IFR partners to communicate freely with one another and with other parties outside the IFR, placing their own firm at the information center. Balancing the roles of influencer and motivator may help the firm avoid the negative effects of information flows on innovation outcome. However, marketing managers must take care in leveraging their R\&D- and marketing-based resources to improve innovation outcomes: R\&D works best when paired with unique, novel sources of innovation from IFR partners, whereas marketing activities are essential for leveraging outside market trends and opportunities that can be combined with strong knowledge accumulation from deep reciprocal relationships.

\subsection{Limitations and Further Research}

Our study has several limitations that indicate opportunities for further research. First, we considered only US firms for our investigation. Interfirm relational practices may vary in international contexts (e.g., [19]). Further research should explore how IFR characteristics may be influenced in an international IFR context, with more relational dynamics, diversification of partnering strategies, and constraints resulting from overseas partnerships. Second, we controlled for contextual factors in the current study, such as industry and technology turbulence. Examining industry and other internal firm contextual effects could enrich our understanding of these phenomena. Third, we used surveys and responses from managers to determine the relational strategies and IFR traits, similar to prior literature (e.g., [4]). However, it is possible that a manager lacks an accurate sense of his or her firm's IFR characteristics and traits. Additional research could take a more structured approach to investigate the network characteristics of the IFRs, using more objective network measures. Fourth, we assume that a firm's IFRs with its partners are stable across time. With this premise, we interpreted the relationships among relational strategies, IFR traits, and innovation outcomes. However, recent research suggests that relationships may change over time (e.g., [67]), so additional studies should explore how changes in relational dynamics and velocity affect a firm's outcomes, such as innovation.

\section{Appendix 1 Measures from the Survey Instrument}

Relational proclivity ([46]; construct reliability $=0.879$; $\mathrm{AVE}=0.593$; range of loadings $0.707-0.826$; scale items anchored by 1 = "strongly disagree" and 5 = "strongly agree")

In general, in my firm the view is that...

1. Close partner-type relationships with suppliers offer a major advantage in doing business.

2. Teaming up and working closely with suppliers allows us to be more effective.

3. Most often, suppliers can be trusted.

4. Most of the time, suppliers will not take advantage of us.

5. Generally, it is okay to engage in close interfirm relationships.

Relational capabilities (formative scale; [47, 76]; scale items anchored by $1=$ "very little knowledge" and 7="lots of knowledge)

Interactional (VIF range: 1.48-2.25):

(1) Negotiating with suppliers

(2) Interactions and contacts for partnering activities

(3) Developing and implementing cooperative programs with suppliers

(4) Building strong communication with suppliers through the use of networked computers

(5) Resolving disagreements with suppliers

Functional (VIF range: 1.92-3.28):

(1) Cost-reduction strategies involving suppliers

(2) Working with suppliers to reduce delivery times 
(3) Working with suppliers on quality management

(4) Integrating suppliers into the firm's just-in-time (JIT) system

(5) Enhancing suppliers' production capabilities and capacities

Initiation (VIF range: 2.12-3.45):

(1) Assessing the match between us and a potential exchange partner

(2) Developing relationships with partners

(3) Evaluating the benefits of a relationships with specific partners

(4) Figuring out when to commit to a partner

(5) Figuring out which exchange partner we can trust

Information flows (newly developed scale based on Patnayakuni et al. [68]; construct reliability $=0.872 ; \mathrm{AVE}=$ 0.630 ; range of loadings $0.749-0.820$; scale items anchored by $1=$ "strongly disagree" and $5=$ "strongly agree")

(1) News about us spreads quickly to our suppliers.

(2) News about our suppliers comes quickly to us.

(3) Our film serves as an information hub for our suppliers.

(4) Our suppliers get news about markets from us.

Relational embeddedness (newly developed scale based on Noordhoff et al. [63]; construct reliability $=0.923$; AVE $=$ 0.751 ; range of loadings $0.787-0.915$; scale items anchored by $1=$ "strongly disagree" and $5=$ "strongly agree")

(1) We have very close ties with our suppliers.

(2) We have strong communication with our suppliers.

(3) We interact on a regular basis with our suppliers.

(4) We believe it is better to have strong relationships with our suppliers.

\section{References}

1. Abernathy WJ, Clark KB (1985) Innovation: mapping the winds of creative destruction. Res Policy 14(1):3-22

2. Almirall E, Casadesus-Masanell R (2010) Open versus closed innovation: a model of discovery and divergence. Acad Manag Rev 35(1):24-47

3. Anderson PF (1982) Marketing, strategic planning, and the theory of the firm. J Mark 46(2):15-26

4. Antia KD, Frazier GL (2001) The severity of contract enforcement in interfirm channel relationships. J Mark 65(4):67-81

5. Armstrong JS, Overton T (1977) Estimating nonresponse bias in mail surveys. J Mark Res 4(3):396-402

6. Barney JB (1991) Firm resources and sustained competitive advantage. J Manag 17(1):99-120
7. Belsley DA, Kuh E, Welsch RE (1980) Regression diagnostics: identifying influential observations and sources of collinearity. Wiley, Hoboken

8. Borgatti SP, Halgin DS (2011) On network theory. Organ Sci 22(5): 1168-1181

9. Bowman D (2012) Evolution of buyer-seller relationships. In: Lillien GL, Grewal R (eds) Handbook of business-to-business marketing. Edward Elgar, Cheltenham, pp 277-292

10. Bowman EH, Hurry D (1993) Strategy through the option lens: an integrated view of resource investments and the incremental-choice process. Acad Manag Rev 18(4):760-782

11. Capaldo A (2007) Network structure and innovation: the leveraging of a dual network as a distinctive relational capability. Strateg Manag J 28:585-608

12. Chandy RK, Hopstaken B, Narasimhan O, Prabhu J (2006) From invention to innovation: conversion ability in product development. J Mark Res 43(3):494-508

13. Chandy RK, Tellis GJ (1998) Organizing for radical product innovation: the overlooked role of willingness to cannibalize. J Mark Res 35(4):474-487

14. Chen I, Paulraj A (2004) Towards a theory of supply chain management: the constructs and measurement. J Oper Manag 22:119 150

15. Chesbrough HW (2003) Open innovation: the new imperative for creating and profiting from technology. Harvard Business Press, Boston

16. Chin WW (1998) The partial least squares approach for structural equation modeling. In: Marcoulides GA (ed) Modern methods for business research. Methodology for business and management. Lawrence Erlbaum Associates, Mahwah, pp 295-336

17. Conner KR, Prahalad CK (1996) A resource-based theory of the firm: knowledge versus opportunism. Organ Sci 7(5):477-501

18. Cui A, O'Connor G (2012) Alliance portfolio resource diversity and firm innovation. J Mark 76(4):24-43

19. Cullen JB, Johnson JL, Sakano T (2000) Success through commitment and trust: the soft side of strategic alliance management. J World Bus 35(3):223-240

20. Day GS (2011) Closing the marketing capabilities gap. J Mark 75(4):183-195

21. De Dreu CKW (2006) When too little or too much hurts: evidence for a curvilinear relationship between task conflict and innovation in teams. J Manag 32(1):83-107

22. Deeds DL, Hill CWL (1996) Strategic alliances and the rate of new product development: an empirical study of entrepreneurial biotechnology firms. J Bus Ventur 11(1):41-55

23. Diamantopoulos A, Winklhofer HM (2001) Index construction with formative indicators: an alternative to scale development. J Mark Res 38(2):269-277

24. Dwyer FR, Schurr PH, Oh S (1987) Developing buyer-seller relationships. J Mark 51(2):11-27

25. Dyer JH, Singh H (1998) The relational view: cooperative strategy and sources of interorganizational competitive advantage. Acad Manag Rev 23(4):660-679

26. Fang E (2008) Customer participation and the trade-off between new product innovativeness and speed to market. J Mark 72(4): 90-104

27. Fang E, Palmatier RW, Grewal R (2011) Effects of customer and innovation asset configuration strategies on firm performance. $\mathrm{J}$ Mark Res 48(3):587-602

28. Fang E, Palmatier RW, Steenkamp JEM (2008) Effect of service transition strategies on firm value. J Mark 72(5):1-14

29. Fornell C, Larcker DF (1981) Evaluating structural equation models with unobservable variables and measurement error. J Mark Res 18(1):39-50

30. Frazier GL, Maltz E, Antia KD, Rindfleisch A (2009) Distributor sharing of strategic information with suppliers. J Mark 73(4):31-43 
31. Frels JK, Shervani T, Srivastava RK (2003) The integrated networks model: explaining resource allocations in network markets. J Mark 67(1):29-45

32. Ganesan S (1994) Determinants of long-term orientation in buyerseller relationships. J Mark 58(2):1-19

33. Ganesan S, Malter AJ, Rindfleisch A (2005) Does distance still matter? Geographic proximity and new product development. J Mark 69(4):44-60

34. Gatignon H, Xuereb J (1997) Strategic orientation of the firm and new product performance. J Mark Res 34(1):77-90

35. Gebauer H, Gustafsson A, Witell L (2011) Competitive advantage through service differentiation by manufacturing companies. J Bus Res 64(12):1270-1280

36. Granovetter MS (1973) The strength of weak ties. Am J Sociol 78(6): 1360-1380

37. Griffin A, Josephson BW, Lilien G, Wiersema F, Bayus B, Chandy R, Dahan E, Gaskin S, Kohli A, Miller C, Oliva R, Spanjol E (2013) Marketing's roles in innovation in business-to-business firms: status, issues, and research agenda. Mark Lett 24(4):323-337

38. Gruber M, Heinemann F, Brettel M, Hungeling S (2010) Configurations of resources and capabilities and their performance implications: an exploratory study on technology ventures. Strateg Manag J 31(12):1337-1356

39. Gulati R, Higgins MC (2003) Which ties matter when? The contingent effects of interorganizational partnerships on IPO success. Strateg Manag J 24(2):127-144

40. Hall BH, Jaffe A, Trajtenberg M (2005) Market value and patent citations. RAND J Econ 36(1):16-38

41. Hauser J, Tellis G, Griffin A (2006) Research on innovation and new products: a review and agenda for marketing science. Mark Sci 25(6):687-717

42. Henderson RM, Clark KB (1990) Architectural innovation: the reconfiguration of existing product technologies and the failure of established firms. Adm Sci Q 35(1):9-30

43. Hess AM, Rothaermel FT (2011) When are assets complementary? Star scientists, strategic alliances, and innovation in the pharmaceutical industry. Strateg Manag J 32(8):895-909

44. Houston MB, Hutt M, Moorman C, Reingen PH, Rindfleisch A, Swaminathan V, Walker B (2004) A network perspective on marketing strategy performance. In: Moorman C, Lehmann DR (eds) Assessing marketing strategy performance. Marketing Science Institute, Cambridge

45. Johnson JL, Lee RP, Saini A, Grohmann B (2003) Market-focused strategic flexibility: conceptual advances and an integrative model. J Acad Mark Sci 31(1):74-89

46. Johnson JL, Sohi RS (2001) The influence of firm predispositions on interfirm relationship formation in business markets. Int J Res Mark 18(4):299-318

47. Johnson JL, Sohi RS, Grewal R (2004) The role of relational knowledge stores in interfirm partnering. J Mark 68(3):21-36

48. Kim SK, Arthurs JD, Sahaym A, Cullen JB (2013) Search behavior of the diversified firm: the impact of fit on innovation. Strateg Manag J 34(8):999-1009

49. Klein R, Rai A (2009) Interfirm strategic information flows in logistics supply chain relationships. Manag Inf Syst Q 33(4):735-762

50. Kohli AK, Jaworski BJ (1990) Market orientation: the construct, research propositions, and managerial implications. J Mark 54(2): $1-18$

51. Krackhardt D, Stern RN (1988) Structuring of information organizations and the management of crises. Soc Psychol Q 51(2):123140

52. Kumar N, Stern LW, Achrol RS (1992) Assessing reseller performance from the perspective of the supplier. J Mark Res 29(2):238253

53. Larson A (1992) Network dyads in entrepreneurial settings: a study of the governance of exchange relationships. Adm Sci Q 37(1):76-104
54. Lee J (2011) The alignment of contract terms for knowledgecreating and knowledge-appropriating relationship portfolios. J Mark 75(4):110-127

55. Lee RP, Johnson JL (2010) Managing the multiple facets of risk in new product alliances. Decis Sci 41(2):271-300

56. Leenders RTAJ, van Engelen JML, Kratzer J (2003) Virtuality, information exchange, and new product team creativity: a social network perspective. J Eng Technol Manag 20:69-92

57. Leonard-Barton D (1995) Wellsprings of knowledge: building and sustaining the sources of innovation. Harvard Business School Press, Boston

58. McAlister L, Srinivasan R, Kim M (2007) Advertising, research and development, and systematic risk of the firm. J Mark 71(1): 35-48

59. Moorman C, Rust RT (1999) The role of marketing. J Mark 63(Special Issue):180-197

60. Morgan RM, Hunt SD (1994) The commitment-trust theory of relationship marketing. J Mark 58(3):20-38

61. Narasimhan O, Rajiv S, Dutta S (2006) Absorptive capacity in high-technology markets: the competitive advantage of the haves. Mark Sci 25(5):510-524

62. Nelson RE (1989) The strength of strong ties: social networks and intergroup conflict in organizations. Acad Manag J 32(2):377-401

63. Noordhoff CS, Kyriakopoulos K, Moorman C, Pauwels P, Dellaert BGC (2011) The bright side and dark side of embedded ties in business-to-business innovation. J Mark 75(5):34-52

64. Osborn RN, Baughn CC (1990) Forms of interorganizational governance for multinational alliances. Acad Manag J 33(3):503-519

65. Palmatier RW (2008) Relationship marketing. Marketing Science Institute, Cambridge

66. Palmatier RW, Dant RP, Grewal D (2007) A comparative longitudinal analysis of theoretical perspectives of interorganizational relationship performance. J Mark 71(4):172-194

67. Palmatier RW, Houston MB, Dant RP, Grewal D (2013) Relationship velocity: toward a theory of relationship dynamics. J Mark 77(1):13-30

68. Patnayakuni R, Rai A, Seth N (2006) Relational antecedents of information flow integration for supply chain coordination. J Manag Inf Syst 23(1):13-49

69. Peteraf M (1993) The cornerstones of competitive advantage: a resource based view. Strateg Manag J 14(3):179-191

70. Raassens N, Wuyts S, Geyskens I (2012) The market valuation of outsourcing new product development. J Mark Res 49(5):682-695

71. Rindfleisch A, Moorman C (2001) The acquisition and utilization of information in new product alliances: a strength-of-ties perspective. J Mark 65(2):1-18

72. Rost K (2011) The strength of strong ties in the creation of innovation. Res Policy 40(4):588-604

73. Rotter JB (1967) A new scale for the measurement of interpersonal trust. J Pers 35(4):651-665

74. Sawhney M (1998) Leveraged high-variety strategies: from portfolio thinking to platform thinking. J Acad Mark Sci 26(1):54-61

75. Simon HA (1981) Bounded rationality and organizational learning. Organ Sci 2(1):125-134

76. Sisodiya SR, Johnson JL, Gregoire Y (2013) Inbound open innovation for enhanced performance: enablers and opportunities. Ind Mark Manag 42(5):836-849

77. Sivadas E, Dwyer FD (2000) An examination of organizational factors influencing new product success in internal and alliancebased processes. J Mark 64(1):31-49

78. Slotegraaf RJ, Moorman C, Inman JJ (2003) The role of firm resources in returns to market deployment. J Mark Res 40(3):295309

79. Sood A, Tellis GJ (2005) Technological evolution and radical innovation. J Mark 69(3):152-168 
80. Sorescu AB, Chandy RK, Prabhu JC (2007) Why some acquisitions do better than others: product capital as a driver of long-term stock returns. J Mark Res 44(1):57-72

81. Varadarajan R (2012) B2B relationship underpinnings of outsourcing. In: Lillien GL, Grewal R (eds) Handbook of business-to-business marketing. Edward Elgar, Cheltenham, pp 400-415

82. Wernerfelt B (1984) A resource-based view of the firm. Strateg Manag J 5(2):171-180
83. Wold H (1985) Systems analysis by partial least squares. In: Nijkamp P, Leitner H, Wrigley N (eds) Measuring the unmeasurable. Kluwer Academic Publications, Norwell, pp 221-251

84. Wuyts S, Dutta S, Stremersch S (2004) Portfolios of interfirm agreements in technology-intensive markets: consequences for innovation and profitability. J Mark 68(2):88-100

85. Zhou KZ, Yim CK, Tse DK (2005) The effects of strategic orientations on technology- and market-based breakthrough innovations. J Mark 69(2):42-60 